\title{
Process of architectural wooden preservation in Japan
}

\author{
T. L. Park \\ Graduate School of Comprehensive Human Sciences, \\ Doctoral Program in World Cultural Heritage Studies, \\ University of Tsukuba, Japan
}

\begin{abstract}
Architectural preservation in Japan is discussed through the study and observation of Gekko-den pavilion at Gokoku-ji Temple in Central Tokyo. Gekko-den's importance lies in its affiliation with Onjo-ji Temple, founded in early Heian Period, 672, a designated National Treasure of Japan, and head temple of the Tendaijimon Buddhist sect. Preservation of Gekko-den commenced in November 2008, and will continue through to October 2013. Historical analysis and overview of Cultural Property definition in Japan and the legal system and administration that functions to oversee the protection and preservation of the cultural properties are examined in detail.

Keywords: wooden preservation, legislation, cultural property, Gekko-den pavilion, agency for cultural affairs, Japanese Association of Conservation and Monuments, training, craftsmen.
\end{abstract}

\section{Introduction}

\subsection{Cultural properties definition, legal structure and administration}

Primarily the word "property" has a legal inference associated with it, one connected with "ownership". Equally the word "heritage" has the values of preservation, conservation and transmission from one generation to another. In Japan, the term cultural properties encompasses an overarching definition of what is essentially viewed as Japan's cultural wealth, that which is safeguarded and secured and handed to future generations.

Cultural Properties include immovable structures such as shrines, temples, natural landscapes, historic districts, and movable objects such as paintings, 
intangible heritage such as, skills, performing arts, craft techniques, traditional events and festivals. The criteria for the Designation of Cultural Properties, as it pertains to buildings; Excellent in Design, Produced with advanced technique, Major historical value, Prominent in the characteristics of any school of architecture in any region, and possessing high value from a scholarly point of view. Under the Japanese Law for the Protection of Cultural Properties, cultural properties are divided into the following eight categories:

Tangible Cultural Properties, Intangible Cultural Properties, Folk Cultural Properties, Monuments, Cultural Landscapes, Groups of Traditional Buildings, Cultural Properties Conservation Techniques, and Buried Cultural Properties.

Those cultural properties considered superior in historic, artistic and scientific value, the government selects, designates, and registers into the following categories; Important Cultural Properties, National Treasures, Historic Sites, Places of Scenic Beauty, and Natural Monuments, affording them priority. As of 1 February 2012, there were 12,816 Important Cultural Properties, of which one fifth were structures.

\subsection{Legal structure}

Legislation as it pertains for the Protection of Cultural Properties has a number of significant historical events influencing contemporary legal guidelines. The Meiji Restoration, from 1868 [1] was a significant turning point signalling the end of military governance by the Tokugawa Shogunate, who had reigned for 250 years from 1600. Meiji restoration implemented a new system of government with the Emperor (from the Imperial household) as the new leader and a parliamentary system employed. The two observed forms of religion, each meeting different ritualistic needs within society, were Shinto and Buddhism. There had been a long history of peaceful co-existence, both religions strongly placed within Japanese society. During the restoration, Shinto was declared as the state religion, leading to a number of anti-Buddhist demonstrations and subsequent violence. A direct result of the conflicts between the two religions was a substantial loss of important cultural properties. In 1871 the government issued a decree for the protection of antiquities, prefectures were ordered to submit inventories specifically identifying objects of significant cultural importance from their region [2]. From 1880 the government provided substantial funds for the preservation of ancient shrines and temples, by 1894, 539 shrines and temples had received subsidies for preservation.

In 1897 the Ancient Temples and Shrines Preservation law was decreed. The law declared that any ancient shrine or temple finding itself financially unable to maintain or repair its buildings, or any other treasure in its possession, may lobby to the government for a financial aid to assist it to meet the associated expenses. The law also directed that a register of buildings under special protection should be kept and maintained, recording name, ownership and location, origin and history, construction and architectural style and detailed measurements.

The law of 1929 for the Protection of National treasures was enacted to circumvent the transfer of proprietorship and in numerous cases the export of national treasures abroad, often traded due to financial hardship by the owners. 
By the enactment of the law in 1929 for the Protection of National Treasures, permits for alterations were introduced as well as increased funding; by this period approximately $70 \%$ of associated costs were covered by the government.
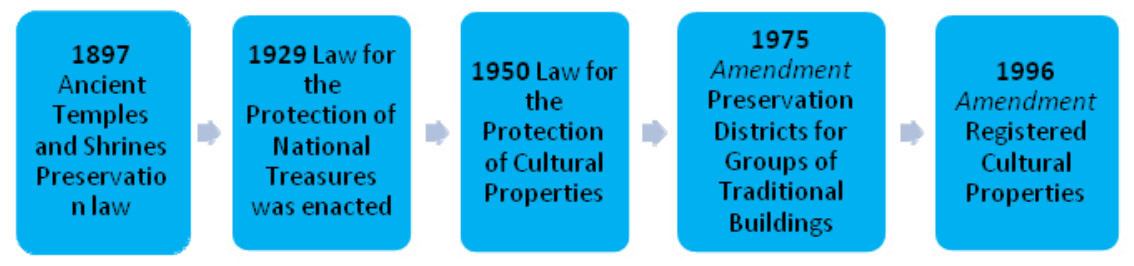

In January of 1949 a fire broke out during preservation of Kon-do Buddhist temple Hōryū in Nara. Hōryū-ji is of notable cultural significance as the temple's pagoda is commonly acknowledged to be one of the oldest wooden buildings in the world, underscoring Hōryū-ji's place as one of the most celebrated temples in Japan. Preservation of Hōryū-ji was during a time of war and the threat of destruction was an impetus for partial dismantlement and storage off-site. Thus when the fire started a significant proportion of the structure was not damaged. Damage was confined to the first (ground) floor and the murals. The charred wooden members were moved to a separate fireproof warehouse for future investigation and research. Through a recent dendrochronological analysis of the wooden materials preserved during the restorations done in the 1950s, it has been determined that some of them were felled prior to $670 \mathrm{AD}$.

The Hōryū fire was the motivation for the enactment of the 1950 law which combined a unified legal framework expanding previous existing laws, and reinforced the protection system. In 1975 the government amended the Law for the Protection of Cultural Properties to include a new category of Important Preservation Districts for Groups of Traditional Buildings. As of October 2010 there are 87 designated districts. There is an important difference at this point when considering cultural property, the difference lies in ownership. Over 70\% of nationally designated structures are religious structures, making the proportion of private ownership low; this is not the case when considering Preservation districts. Private ownership rights are strong in Japan, some owners view designation as a restriction to individual rights, whilst others are more accepting due to the opportunities that often arise from designation. In some cases, designation has meant the survival of remote towns which was threatened due to rapid modernisation and industrialisation in the 1950s and out-migration by young people from rural areas to large metropolitan cities of Tokyo and Osaka.

An amendment in 1975 included the system for the protection of Conservation Techniques for Cultural Properties, an important step in acknowledging the skills and techniques associated with preservation as being an essential part of preservation.

In 1996 a system of Registration of Cultural Properties was implemented, registered cultural properties having fewer stringent rules to be adhered to by the owners, generating a wider appeal to a broader range of people. Through the registration system a significant number of buildings have been identified that 
were unable to be protected as important cultural properties, now numbering over 25,000 .

\subsection{Government and administration}

From the enactment of the 1897 Ancient Shrines and Temples Preservation Act, the Minister of State, on consultation with the Commission for the Preservation of Ancient Shrines and Temples, would determine which buildings to select for protection.

In 1968 the Agency for Cultural Affairs (ACA) was established, along with the Council for the Protection of Cultural Properties via a merger of the Cultural Bureau of the Ministry of Education and the Cultural properties Protection Commission. Its main tasks are three-fold; the promotion of culture, administration affairs of state religion, and the preservation and utilization of cultural properties. The preservation of cultural properties is administered by the Cultural Properties Department of which the Architecture Division is one of four. The Architecture Division manages the preservation of protected buildings and associated districts, and also formulates proposals for new designations. Furthermore in operation is a Council comprised of five members appointed by the Minister of Education, Science and Culture (MEXT) who are learned people regarding culture plus an additional 10-15 members with extensive knowledge in Architecture, conservation and history. The council investigates, deliberates and advices on; Designation of National Treasures and Important Cultural Properties, The repair of National Treasures, Recognition of holders of Traditional Conservation Techniques, and Proposals for alterations to an existing state.

\subsection{Architectural conservation}

(i) Under the guidance of the Agency for Cultural Affairs in 1971 Japanese Association for Conservation of Architectural Monuments [JACAM] was established. The primary rationale was to introduce employment stability within the preservation sector. Kyoto, Nara and Shiga contain numerous important cultural properties, subsequently there were large numbers of restoration projects and employment was continuous. In other areas across Japan employment was often confined to singular restoration projects. Upon the establishment of JACAM, people who had previously been hired for singular projects were offered permanent employment and subsequent stability.

One of the main functions of JACAM is the education and training of architectural conservators. Regular courses are held for architectural conservators and carpenters specializing in restoration, there are separate courses for architectural conservators and carpenter each at different skill levels.

(ii) Financial assistance by the Japanese government from the early 19th centrally has always been a central theme, and continues to the present day. Approximately $90 \%$ of nationally designated buildings are of wood construction. Furthermore half of the structures roofs are composed of natural plant fibres such as thatch, wooden shingle, cypress bark, rendering them particularly vulnerable 
to fire. Subsequently fire prevention facilities are of the utmost importance and there is governmental support providing subsides for owners or custodial bodies to install or maintain fire-prevention equipment.

(iii) For preservation projects of important wooden cultural properties throughout Japan, where partial or full dismantlement is commenced, (decision being wholly dependent on the overall condition and damage to the structure), a commonality of procedure exists. Initially a survey is undertaken to ascertain the over-all state of the structure. A preliminary conservation plan is created. Construction of scaffolding encasing the building in entirety occurs, and partial dismantlement of the building begins.

During the dismantling process, a detailed analysis of the structure is undertaken. A ground survey is undertaken to assess seismic capacity, and the full extent of damage and the cause is ascertained. After the 1995 Hanshin earthquake seismic assessment regulations were deemed compulsory Additional information studied is wood species, age and style, dimensions and finish, joint connections, usage for other purposes and sumi (inked) writings. Historical documentation is also consulted in the form of maps, writings and photographs. Based on findings, a final preservation plan is generated. If structural reinforcement is required, increase in associated costs and duration of preservation project can rise dramatically, and a design engineer is required fulltime on site. Once the preservation plan is finalized, an order is placed with contractor and preservation work commences.

Upon completion of the restoration work, a report is published, included detailed surveys conducted for the restoration work, record of the restoration work and subsequent findings of the historical survey of the building, drawings and photographs before and after restoration. The final report is mandatory for restoration projects where full or half dismantlement has occurred and repair work that employed specialized techniques. As previously mentioned documentation was introduced in the Meiji era, the production of measured drawings using traditional ruling pen, blades, ink and brushes are created, from the Meiji era are still practiced. Reports are printed and distributed to conservation architects and libraries across Japan, assisting in the dissemination of knowledge, and estimation of future cost projections for restoration projects.

\section{Gekko-den pavilion}

Gekko-den pavilion was designated as a National Treasure in January 1931 and redesignated as an Important Cultural Property in 1950. The budget for Gekkoden is covered by the National Government, Tokyo Metropolitan, Bunkyo Ward Government, and the custodial owner. Full dismantlement restoration work commenced in November 2008 on and will continue through to October 2013.

Gekkoden pavilion at Gokoku-ji temples dates from the Edo period, built in early 1600's, as a guest room for Nikko-inn, a subsidiary temple of Onjo-ji in Shiga Prefecture. In 1894 the building was purchased by a businessman and moved to his private residence in Shinagawa, Goten-yama. In 1928 the building was moved to its current location at Gokoku-ji Temple and renamed Gekko-den, 
meaning Moonlight Pavilion. There are many examples of cases where buildings have been transported to different sites or significantly remodelled for change of purpose. Katsura palace, in Kyoto, is one such example where traces of such change are evident. Frequently in these cases dismantled timbers were given a second life.

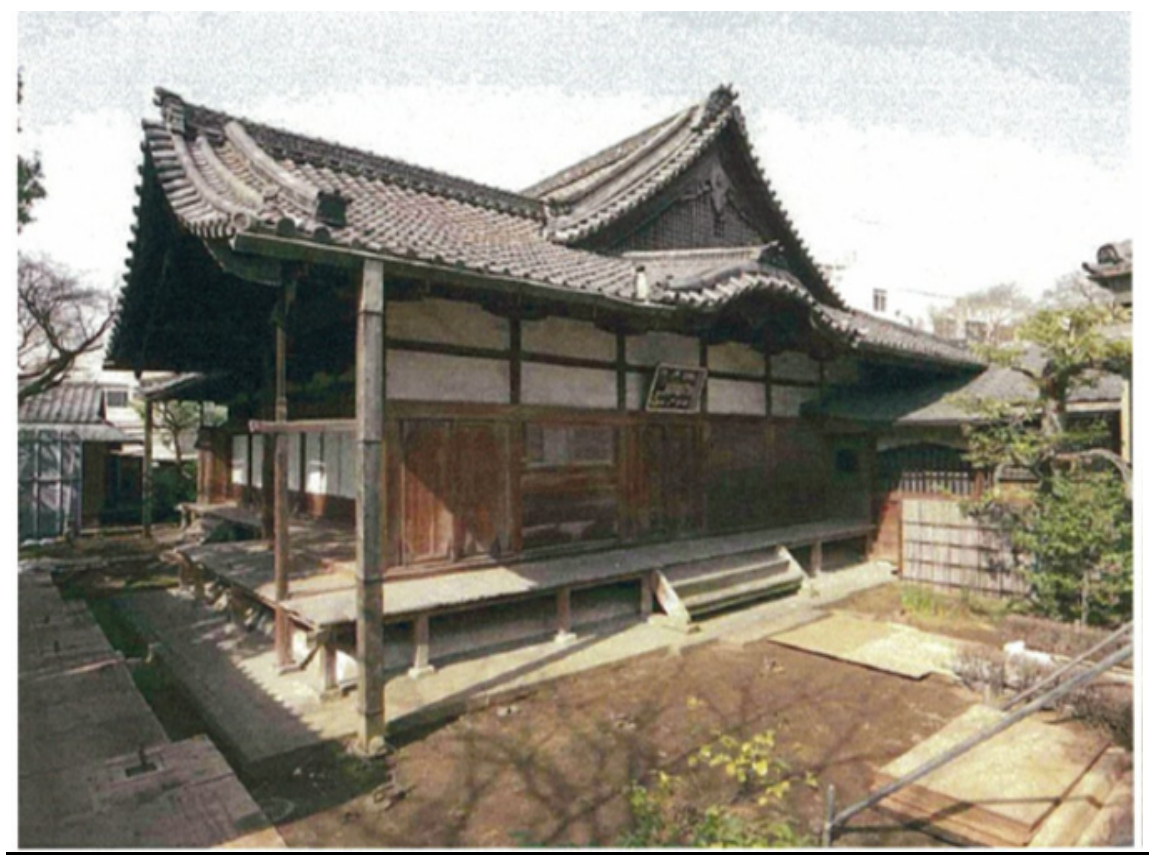

Figure 1: Gekko-den pavilion prior to preservation.

During the eighty years following the move of Gekko-den to its current site, the structural members had begun to show obvious weakening. Depression of the ground under the flooring system was extensive, deformation and sinking of the structure had become significant. It was due to these contributing factors, the decision for full dismantlement was made.

Whilst each wooden structure is unique in design and composition, there are commonalities between the aging of the structure and certain areas in which replacement occurs. The exposed perimeter of the structure, close to the ground is often a place where moisture damage occurs. Additionally the weight of roof tiles can cause declination of the angle of eaves under heavy constant loadings and this was also evident at Gekko-den pavilion. Roof loading is one of the weaker elements in traditional structures with heavy mud beds beneath the roofing tiles. It is possible to reduce weight by reducing the mud thickness. Roofs utilizing organic thatch and cypress result in even further reduced loading. In the case of Gekko-den the original cypress tile roofing has been re-installed, replacing heavy ceramic tiling, common amongst Japanese buildings. 
Gekko-den is a single story structure with a side of roofing that extends out and up from each side of the rectangular structure. Partway up two of the shorter opposite sides stop and the remaining two continue to the top where they are joined. The Irimoya style roof was considered the most elegant of the Edo period; the top level of all castles has an Irimoya roof style.

The main building has a carriage porch and an inner gate which is reflective of the Shuden-zukuri style in Muromachi Period (1338). According to the building method or typological study, Gekko-den is distinctive because it is considered to be built at the beginning of Edo Period, similar to Kojo-in (subtemple of Onjo-ji Temple) and Kangaku-in Kyakuden [3].

The design is post and beam construction; joints are used to combine pieces of wood in straight longitudinal direction or angles, such as the curved ends of the eaves. The traditional wood jointing system deployed throughout connects wooden members with specialized joints, for which Japanese architecture is admired and well known. The underlying principle behind such construction is that the building is held together with a complex jointing arrangement. It is this complex design, so integral and fundamental to Japanese architecture that over hundreds of years, due to the natural properties of wood, structural loading, climatic wind loadings and seismic action, the connections and joints loose structural strength. The tightness of the interlocking of the jointing system becomes weakened and needs partial or full replacement. The excellence of Japanese carpentry practice comes to the fore, with a strong correlation between the skill of carpentry and the beauty and strength of the building where strong, precise jointing can significantly prolong the life-span of the structure. As mentioned there are two common methods deployed, partial and full dismantlement. In essence the building is taken apart from the roof down, examined in detail, the structurally deficient parts are fixed or replaced and then the building is put back together. Nobuo Ito has commented that the roof and its immediate supporting members are typically dismantled about every 150 years and full dismantlement of the building occurs about every 300 years in the lifespan of the building. However, it is important to note that although this is a general time-frame applicable to wooden preservation throughout Japan, there is no intent to restore buildings at fixed intervals, but to preserve them when deemed necessary; such is the case of Gekko-den Pavilion.

Additionally there is a mistaken belief regarding the ritualistic dismantlement of all heritage structures throughout Japan. This process is attached to religious Shinto ritual, and specifically to Ise shrine. The term "Shikinen Sengu" is the Japanese term used regarding the rebuilding of a structure at set intervals, namely 20, 30 or 50 year intervals. Smallness of scale of the structure, common in Shinto, renders the rebuilding comparatively straight forward. Shinto ideals of purity are stringently adhered to throughout the rebuild to exacting detail; this is exclusively a primitive Shinto ritual and is performed on a singular shrine considered of great importance, the Ise shrine [4]. During 2013 Ise shrine will be rebuilt for the 62nd time. 


\section{Process of Gekkoden pavilion preservation}

\subsection{Temporary shelters and scaffolding}

Traditional scaffolding in Japan utilises bamboo as its main material, a seen in the World Heritage Sites in Nikko. Provisional shelters and steel scaffolding were used for the first time in 1973 in Kyoto for the conservation of the main gate of the Tohfuku-ji temple. The use of temporary steel framed shelters is now common across preservation sites in Japan. Due to the height of some temples and the subsequent weight of the scaffolding, it can cause damage to vegetation and archaeological artefacts, thus the footings and erection of scaffolding are carefully considered. In the case of Gekko-den scaffolding was erected taking into consideration trees on site. Space surrounding Gekko-den is limited due to the close proximity of additional dwellings, thus there is no room for large mechanisms such as cranes. Lifting of large beams is done by hand, and with the use of winches and chains. An external sloping ramp is used to provide connection between two levels.

The purpose of scaffolding serves to protect the building whilst preservation takes place, additionally due to its size and design doubles as a valuable means of storage of wooden members. Attached to the interior sides of the scaffolding is an alpha/numeric grid system which enables exact cross referencing whilst work is being conducted. The grid is overlaid on architectural drafted plans and referenced throughout restoration work.

\subsection{Dismantlement}

Number plates have been attached to each individual member indicating the location and orientation of each, and detailed drawings of the structure made. The structural frame has been disassembled and damaged or deteriorated parts have been repaired or replaced as necessary. At Gokoku-ji architects and carpenters conducted an investigation of the building, looking at the materials, building techniques and dimensions in order to study the history of the building. Such investigations pertaining to the historic building are considered a very important part of the preservation process, and can reveal building techniques and elucidate much history surrounding the structure. At Gokoku-ji historical findings by the lead architect were presented to ACA for deliberation, along with extensive documentation including historical information tracing back the design of Onjo-ji and the importance of this building to Gekko-den. The findings provided the basis for restoration to an earlier design state, considered it's most significant and true state and an example of architectural history at that period of Japanese history.

\subsection{Discoveries and decisions}

During the disassembly and examination process, inspection of original members revealed saw lines and pulling actions of the saw during the building of Gekkoden at the beginning of the Edo Period (1600 onwards). Methods of lumbering 
and processing timber have been explained by Nobuo Ito. Basically to process trees an axe was used to fell and large crosscut saws with single or double handles for two people handling were used. Large ripsaws were used after their introduction from China in the fifteenth century. The introduction of sawmills to Japan lagged behind Europe and North America. The Taisho period (19121926) saw the introduction of machine manufacture of saws. Subsequently the Showa era (1926-89) became the time for the use of power tools. William Coaldrake [5] noted that as late as the middle of the twentieth century Japanese carpenter's tools and techniques were still basically traditional. At Gekko-den a combination of contemporary and traditional tools are used. Electric tools are used primarily for the cutting, but traditional hand tools are used for the final finishes and shaping. The use of traditional hand tools for finish work ensures that the final appearance of the building matches that of its predecessors, and ages in similar fashion. At Gekkoden pavilion the osae-biki is used for providing an exacting flush, level surface. The Adze is used to skim off the outer molecular surface of the wood, creating a barrier, thus providing a superior resistance to moisture penetration, along with aesthetic similarities in the wood.

Indentations and nail holes revealed previous placement of members, additions and access pathways. Such indentations have been studied in detail, and every hole is identified and marked with chalk. This is important as traditional Japanese nails are iron forged, square in shape, whilst newer holes are circular, identified as western nails. When studying the square traditional Japanese nail markings, the actual size of the nail hole is important, and studied in detail. The changes and similarities of nail size provides supplementary information regarding the age of the nail, which can be dated more accurately, and additionally comparison throughout the entire structure provides further clues and evidence of previous procedures, modifications, and so forth.

During the Meiji Restoration (1868-1912) standardization of measures were adopted by Japan along with the western (circular) style nails [6]. It is now understood that Japanese traditional forged nails made from iron sand are preferable to the modern rolled steel nails which swell as the iron oxide replaces the iron during rusting and cause cracks in wooden members.

At Gekko-den Hinoki, or Japanese cedar, has been used for the main structure and Matsu, Japanese pine, for the roof. It is becoming increasingly difficult to source Hinoki and timber merchants often purchase Hinoki and stockpile, waiting for prices to rise. It is up to the architect to negotiate with dealers for the Hinoki and to determine the final costing. The cell structure of Japanese Hinoki is favoured by carpenters for its straight grain, and colour.

Using the same wood type or the closest similar type is considered to be of the utmost importance by carpenters and architects. By using the same wood, the wood acts and corresponds to weathering and biodegradable factors in the same way, thus this gives the structure a unity and completeness in design which will continue in the future aging process of the building. It is understood that significant dimensional changes occur because of gain or loss of moisture, and that this may vary in the three grain directions; Size changes about 6 to $16 \%$ tangentially, 3 to $7 \%$ radially, but only 0.1 to $0.3 \%$ longitudinally. Japan has a 
temperate climate with very low humidity in winter months and hot summers with very high humidity, often over $90 \%$. Such drastic fluctuations in humidity cause the wood to swell and shrink repeatedly. Cracks caused by expansion and contraction of wood in Japans climatic extremes are accepted as patina and not covered.

Standardization and prefabrication of components was common practice and as a result of modular proportioning geometric calculations used by carpenters became well established, a system known as kiku and kiwari. When parts of a building need to be replaced, carpenters are able to reproduce the missing original components using the kiku and kiwari methods. There are examples of buildings being returned to a previous state because original members such as eaves have been located, stored within the structure, and the original member used as a proto-type to reproduce original design.

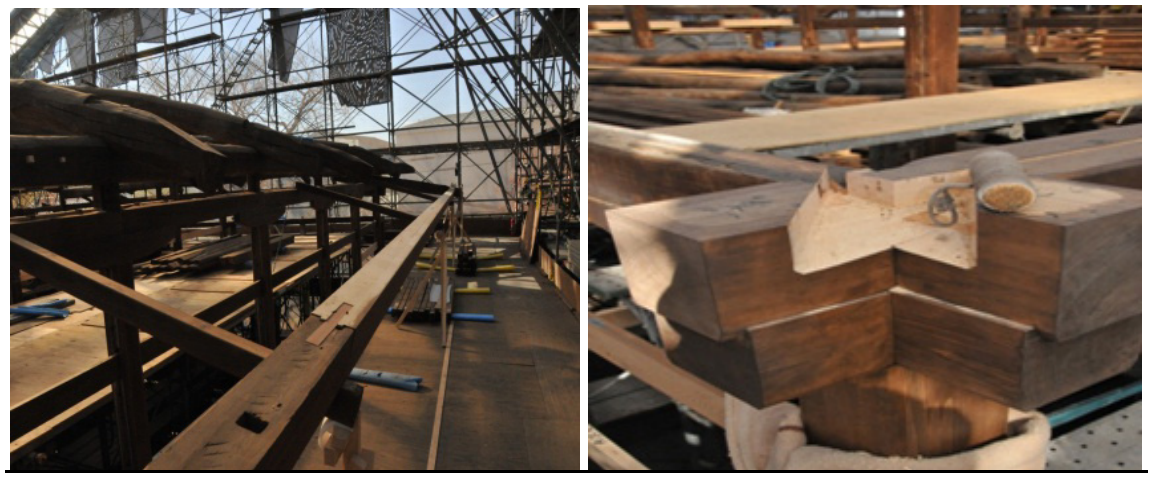

Figure 2: $\quad$ Examples of Tsugite and Shigushi jointing.

Two main methods of joints are generally deployed, Tsugite and Shigushi. Due to the obvious limitations of the possible length of wood, where a continuous member is required, intricate and involved jointing methods have evolved to create an uninterrupted linear member. The name for lengthening joints is Tsugite, due to the necessity with which these joints are required; there are 50 types of Tsugite joints deployed by Japanese carpenters. Shigushi is a system developed for securing members at oblique and right angles; generally there are eight types of angle joints deployed. Complex joints and detailed members are intricately measured and carved in a separate carpenter's room, within the temple grounds. A large template is fashioned; on the surface are 1:1 drawings of curved struts and complex joints. The entire floor is covered in white card, shoes are removed and the area used to draw one to one scale of composite joint. Models are also evident on site of the cypress bark roofing, clearly depicting the thickness of the bark, copper flashings and connections to the roofing structure.

It is imperative that all respective wooden members fit exactly into positions indicated in the drawings, for flush jointing connections. Accordingly it is necessary that ink lines are drawn onto the woods surface are flawless. Kikujutsu 
(stereometry) enables master carpenters to draw only with the help of an Lshaped square. The inked timbers are all cut and planned to instructions and then assembled. Kikujutsu is now placed under government protection as one of Japanese Traditional techniques.

\subsection{Seismic factors and considerations}

Utilising Gekkoden as a case study is effective in highlighting the generic processes employed across preservation sites across Japan. The decisions made are in line with conservation principles and meet the approval by the committee for preservation. What sets Gekkoden apart, and why this structure is of particular interest, is owing to the decision to employ seismic retrofitting, a procedure that is un-representative for preservation of Japanese cultural properties. The decision surrounding the implementation for base isolation was made due to a number of contributing factors; Gekkoden does not exist in the original site, subsequently decisions surrounding the disturbance and loss of important archaeological strata and artefacts does not apply; seismic retrofitting ensures the survival of the valuable scroll paintings contained within the structure; and due to significantly high numbers of people visiting the site, human safety and concern for human life was an important consideration.

In Japan alongside the material vulnerability from fire is the continuous peril of earthquakes, Jishin in Japanese. At the end of the Edo period and the beginning of the Meiji restoration, like elsewhere world-wide, new developments of scientifically based building codes were adopted. The Architectural Institute of Japan (AIJ) was formed in 1886, and by 1888 the first city planning legislation was in place and the formation of the Earthquake Investigation Committee followed in 1891.

Japan measures earthquakes using the Shindo scale, which relates to the actual intensity of the wave motion at the earth's surface, i.e. how much the building actually moves. Conversely the Richter scale measures the intensity of the earthquake at the epicentre, which can be many kilometres underground. Shindo literally means 'degree of shaking' the Japan Meteorological Agency recognises 10 levels. Shindo 0 is a very light tremor; Shindo 5 causes damage to wooden houses, roads, gas pipes. The great eastern Kanto earthquake of 2011 was Shindo 7, magnitude 9.

Gekko-den pavilion was evaluated for seismic performance prior to preservation. Investigations revealed structural weaknesses, sufficiently serious that total collapse was a distinct possibility. High visitor numbers dictated seismic retrofitting was required. Subsequently decisions were made for the installation of base isolation, including fixing of the pillars to the isolation unit (original design is of pillars resting on foundation stones). Base Isolation is a technique where a horizontal sliding mechanism is introduced at the foundation level. This effectively allows the ground to shake under the building without the amplitude of the waves being transmitted through to the building. The employment of a base isolation system, while both expensive and complex, does afford high protection in earthquake prone regions. 


\section{Future directions}

Japan has an established history of preservation of National treasures and Important Cultural properties. Two key themes are of importance as wooden preservation efforts move forward into the 21st century.

Japan has recognised the Importance of laws to protect skills and techniques associated with the preservation of historic structures. Individuals and organisations have been recognised as possessing specialised restoration techniques seen as indispensable for the preservation of cultural properties, skills such as the kiku technique for marking parts of the curved eaves using carpenters square. Individuals are recognised as 'Holders' and organizations as 'Organizational Holders of Important Intangible Cultural Properties”. Holders are requested to keep their knowledge and transmit it to their successors, the government grants subsidies, amounting to 1.5 million yen per person per annum. Along with the interdependency on traditional skills and knowledge is the access to materials for preservation. There is an understanding within the wooden preservation circles globally, of increasing difficulty associated with obtaining materials. Replacement and connections with wood of the same quality i.e. pine in Norway or Hinoki in Japan is imperative of structural strength, weathering and so forth. Difficulty in obtaining materials has increased significantly post 1970. In 2006 the government established an initiative called "Forests for Heritage" with the primary aim of securing the necessary materials for preservation, such as Hinoki timber wide in diameter and long in length, and cypress bark. In April 2010, nine prefectures were identified and designated as areas for heritage materials.

Finally, in the past there have been discussions concerning full dismantlement, the loss of original material, and the relationship between material and authenticity. Dismantlement is a rational action, one that ensures survival of people and associated structures across Japan.

\section{References}

[1] Huffman, James, L. Japan in World History, 2010. Oxford University Press Inc. 198 Madison Avenue, New York, NY 10016.

[2] Henrichsen, C. 1998. Historical outline of conservation legislation in Japan. HOZON - Architectural and Urban Conservation in Japan, 12 - 21.

[3] Nishi, K. and Hozumi, K. 1983. What is Japanese Architecture? A survey of traditional Japanese architecture. Shokokusha Publishing Co. Ltd., Japan.

[4] Adams, C. 1998. Japan's Ise Shrine and its Thirteen Hundred Year old Reconstruction Tradition. J. Architectural Education. 52, 1, 49 - 60.

[5] Coaldrake, William. 1991. The Way of the Carpenter: Tools and Japanese Architecture, Weatherhill, Tokyo.

[6] Sekino, Tadashi. The Conservation of Ancient Buildings in Japan, World Engineering Congress, Tokyo, 1929. Reprinted by The Japanese Committee for ICOMOS, 1989. 